\title{
Allergen Avoidance in Asthma: Is There a Role?
}

\author{
Nicola J. Gray, $M B$ \\ Anthony J. Frew, $M D^{*}$
}

\author{
Address \\ *Department of Respiratory Medicine, Royal Sussex County Hospital, Eastern \\ Road, Brighton, BN2 5BE, UK \\ Email: anthony.frew@bsuh.nhs.uk
}

Published online: 16 January 2014

(C) Springer International Publishing AG 2014

Keywords Asthma - Allergen - House dust mite - Avoidance

\section{Opinion statement}

Asthma is a heterogeneous disease with symptoms that fluctuate in scale and severity throughout life. Whilst allergic triggers have been implicated in both its development and subsequent exacerbations, there is no conclusive evidence that allergen avoidance in infancy prevents subsequent development of asthma. Recent studies suggest that allergen avoidance is not an important management strategy in established asthma.

\section{Introduction}

\section{Epidemiology}

Asthma is one of the more common chronic diseases, affecting approximately 300 million people worldwide [1]. Until recently, prevalence in the West has been increasing, but figures now seem to have stabilised [2]. Asthma spans all age groups and carries significant direct healthcare costs as well as the indirect costs of work days/school days lost due to illness [3]. As the population ages, asthma is likely to become an increasing problem in the elderly, where drug interactions and comorbidities may make treatment more complicated [4]. The worldwide death rate from asthma is estimated at around 250,000 per year [5]. In the UK, deaths from asthma have been linked to socioeconomic disadvantage, suggesting that some deaths may be preventable [6].

\section{Diagnosis}

There is no "gold-standard" definition of asthma, which can be problematic with respect to accurate diagnosis of the disease, particularly in children. This is especially relevant when asthma development is an endpoint in clinical trials. Classic symptoms common to all definitions include dyspnoea, chest tightness, cough, wheeze, and variable airflow obstruction. Common triggers include exercise, exposure to pets, and cold or damp air.

The diagnosis of asthma in children relies on the recognition of classical signs and symptoms described above. However, these features are also present in other conditions. Viral infections, for example, often present very similarly to asthma in childhood. Indeed, children presenting with wheeze before the age of 2 years are less likely to have asthma later in childhood [7], although frequent or severe wheezing episodes are associated with increased risk of 
asthma development [8]. Coexistent atopic disease such as eczema and rhinitis is also linked to the development of asthma, as is maternal atopy $[7,9]$. Clinical history, therefore, can be used to assess the probability of asthma, and initial treatment can begin without the need for further tests.

Where the history is less convincing, an assessment of airflow obstruction can be used to support a diagnosis of asthma. Normal spirometry does not preclude diagnosis of asthma, particularly if testing is performed when the child is asymptomatic. Asthma is the most common cause of airway obstruction in children. A FEV 1 / FVC ratio of less than 0.7 lends support to the diagnosis of asthma. An increase of greater than $12 \%$ from baseline in forced expiratory volume in 1 second $\left(\mathrm{FEV}_{1}\right)$ or increase in peak expiratory flow (PEF) following treatment with bronchodilators is also highly suggestive of the disease. Spirometric values correlate poorly with reported symptoms and the use of asthma medications [10], and formal lung function testing in children under the age of 5 years is challenging and involves the use of techniques that are not widely available. When diagnostic uncertainty exists, a trial of treatment may be indicated. This strategy is recommended by the British Thoracic Society in its asthma guidelines [11].

In adults, when there is a good history of asthma symptoms and spirometric evidence of obstruction $\left(\mathrm{FEV}_{1} / \mathrm{FVC}\right.$ ratio $\left.<0.7\right)$, most clinicians would initiate a trial of treatment for 6 to 8 weeks, and then reassess. In cases with normal spirometry where history is atypical or with typical history yet normal spirometry, further investigation may be required. A significant increase in $\mathrm{FEV}_{1}$ (>12 \% from baseline) or PEF following bronchodilation can provide additional evidence for an asthma diagnosis. Airway hyperresponsiveness (AHR) can be assessed with a methacholine or histamine challenge, in which $\mathrm{FEV}_{1}$ is assessed at set intervals following inhalation of the challenge substance. Increasing doses are used, and the response is quantified as the provocative dose causing a $20 \%$ fall in $\mathrm{FEV}_{1}\left(\mathrm{PC}_{20}\right)$. In a normal population, $90-95 \%$ have a $\mathrm{PC}_{20}$ of $>8 \mathrm{mg} / \mathrm{ml}$, and the likelihood of asthma increases when small doses are required. Fractional exhaled nitric oxide concentration $\left(\mathrm{FE}_{\mathrm{NO}}\right)$ can be used to assess eosinophilic airway inflammation. A $\mathrm{FE}_{\mathrm{NO}}$ of $>25 \mathrm{ppb}$ at $50 \mathrm{ml} / \mathrm{sec}$ is seen in $70-80 \%$ of patients with untreated asthma. As increased $\mathrm{FE}_{\mathrm{NO}}$ may be present in other conditions, this test may be better as a predictor of response to treatment with corticosteroids than as diagnostic for asthma.

\section{Pathophysiology}

Asthma is a clinical syndrome involving several different pathways that can lead to variable airflow limitation and breathlessness. As such, although its pathogenesis is still not entirely understood, it seems likely that both genetic and environmental factors are involved. Genome-wide association studies have identified a number of genes thought to be linked to asthma. Not all of the data have been reproducible, and the loci identified account for only a small proportion of the heritability of the disease [12]. None of the loci discovered overlap with those responsible for IgE concentrations, which may support the theory that atopy is not the primary driver of asthma susceptibility. However, it may also be possible that the correct locus has not yet been identified.

Asthma itself has a wide range of clinically observable characteristics, which has led investigators to describe multiple asthma phenotypes. Whether these remain stable or change during the course of the disease is unclear [13]. Some of the postulated asthma phenotypes are described in Table 1. This is subject to change, and different investigators have described different phenotypes [13-15].

In most cases of asthma, symptoms occur due to chronic inflammation of the airways. It has been proposed that aeroallergens such as pollens, moulds, house dust mites, cockroaches, and animal dander encountered in infancy induce allergic sensitisation, which in turn primes the airway mucosa, allowing asthma to develop in genetically susceptible individuals. Airborne allergens deposited in the airways are captured by dendritic cells and presented to T lymphocytes. This stimulates the production of Th2 cytokines, including interleukin 4 (IL-4), interleukin 5 (IL-5), and interleukin 13 (IL-13). These cytokines (IL-4 and IL-13 in particular) promote the formation of IgE antibodies, which attach to receptors on the surface of mast cells and basophils. Upon the next allergen encounter, IgE cross-linking results in mast cell degranulation and the release of histamine, leukotrienes, and prostaglandins, all of which are potent bronchoconstrictors. Additional Th2 cytokines (mainly IL-5) cause eosinophils to migrate to and accumulate in the airways. Persistence of eosinophils in the airway mucosa is a hallmark of allergic asth$\mathrm{ma}$, but it is also seen in non-allergic forms of the disease.

Sensitisation to allergens, particularly house dust mite, has been shown to increase the risk of developing asthma, and exposure to these allergens increases morbidity [9, 16]. Some studies have found that multiple early allergen exposures predict the presence and persistence of asthma in children $[16,17]$. It has been hypothesised that preventing allergen sensitisation in children may reduce the chances of developing asthma later in life. Avoidance of allergic triggers in established asthma has also been postulated to be of benefit in the management of the disease $[18,19]$.

Despite novel therapies, asthma remains an incurable disease, and so the prevention and reduction of exacerbations are attractive prospects. 
Table 1. Asthma phenotypes

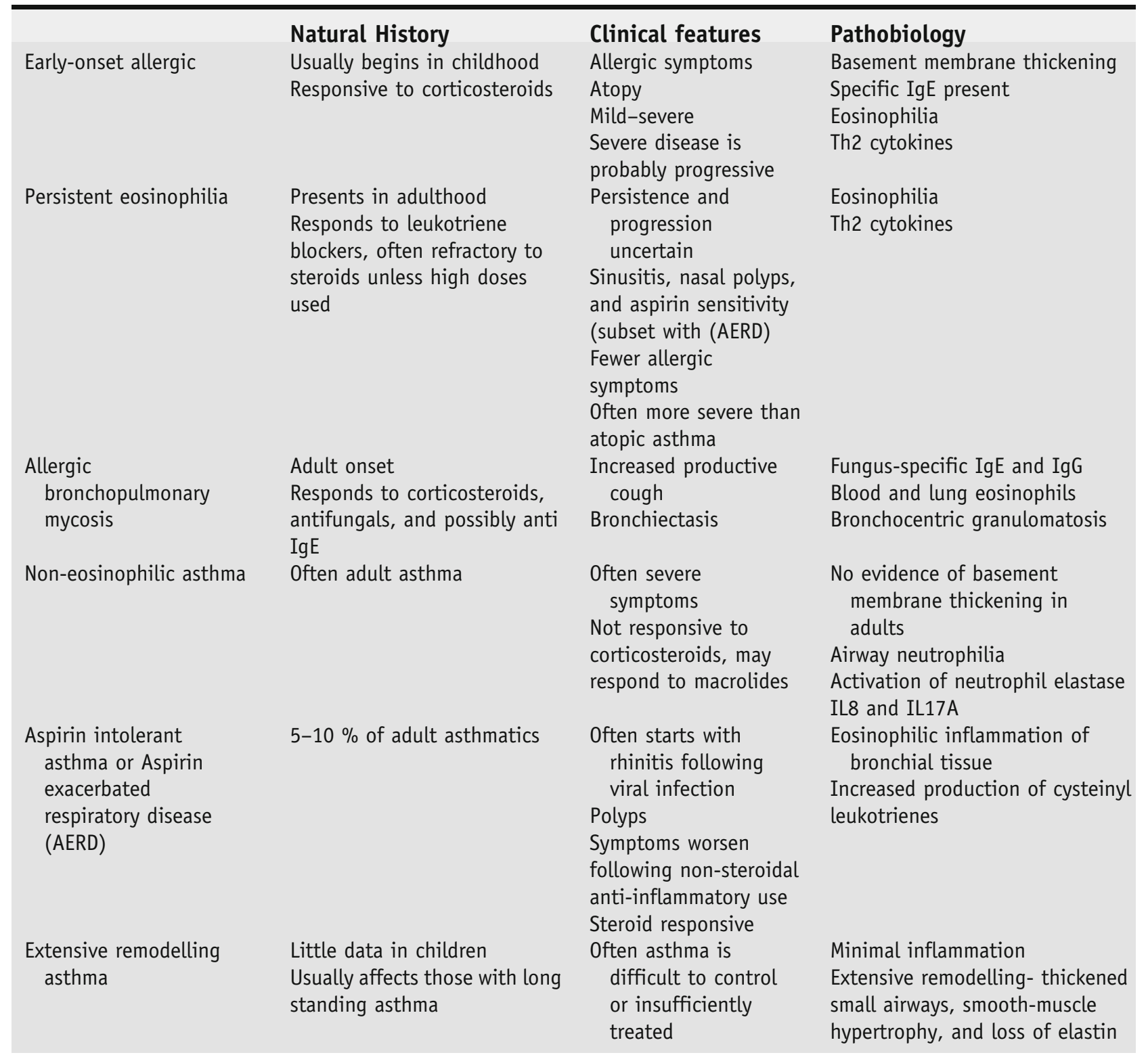

\section{Allergen avoidance}

Primary prophylaxis

Seven large studies have investigated whether allergen avoidance in infancy can affect the subsequent development of asthma. Four of these have recently published follow-up data. These studies are discussed below.

The Isle of Wight study

In a study commenced in 1990, 120 infants considered at birth to be at high risk of atopy were recruited and then followed up at ages 1 , $2,4,8$, and 18 years $[20 \bullet, 22,23]$. Participants were randomised to prevention and control groups. In the prevention group, lactating 
mothers and infants avoided dairy, egg, soya, fish and shellfish, peanut, and tree nut until the infant reached 12 months of age [20•]. House dust mite (HDM) reduction measures were also undertaken by use of both mattress covers and acaricides [20•, 21]. At follow-up, questionnaires regarding asthma and allergy symptoms were administered, and physical examination and skin prick tests (SPTs) were performed [21]. At ages 8 and 18 years, participants underwent spirometry and methacholine challenge testing [20•, 21]. There was no significant difference in the rates of physician-diagnosed asthma at age 2 or 4 years [22]. At age 8, there was no difference in symptoms ofcurrent wheeze $(p=0.08)$ and exercise-induced wheeze $(\mathrm{p}=0.3)$, as assessed by questionnaires [21]. Nocturnal cough was more common in the control group $(p=0.02)$. When asthma was defined as the presence of wheeze and bronchial

hyperresponsiveness, there was no significant difference between the groups at age 8 [21].

At 18 years of age, 114 of the original 120 participants were assessed, and patients were classified into one of four groups: persistent asthma, late-onset asthma, remitted asthma, or never asthma [20•]. Rates of persistent asthma were lower in the prevention group than the control group $(\mathrm{p}=0.04)[20 \bullet]$. However, there was no difference between the groups for late-onset asthma $(p=0.38)$, remitted asthma $(\mathrm{p}=0.5)$ or never having been diagnosed with asthma $(\mathrm{p}=$ $0.18)[20 \bullet]$.

The childhood asthma prevention study (CAPS)

This was a randomised controlled trial investigating the effectiveness of HDM avoidance and omega-3 fatty acid supplementation from birth

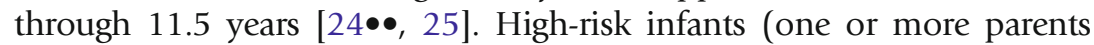
or siblings had asthma or wheeze) were recruited before birth. Those living in homes with cats were excluded. Participants were allocated to one of four groups (Table 2) [25]. All groups were given advice on appropriate ventilation, regular vacuuming, and avoidance of humidifiers/vaporisers $[25,26]$.

Participants were followed up at 18 months and 3, 5, 8, and 11.5 years, at which time they were interviewed via questionnaire about symptoms relevant to asthma. At age 5 years and older, spirometry was measured and SPTs were performed $[24 \bullet \bullet, 25,26]$. Probable current asthma was defined as a parental report of any

Table 2. Group allocation and interventions performed in the CAPS study

\begin{tabular}{|c|c|}
\hline Group & Intervention \\
\hline A & $\begin{array}{l}\text { Placebo diet - polyunsaturated margarines and oils, Sunola oil supplements } \\
\text { No HDM reduction - standard advice and normal washing routines }\end{array}$ \\
\hline B & $\begin{array}{l}\text { HDM reduction - standard advice, allergen impermeable covers, acaricide wash } \\
\text { Placebo diet- Polyunsaturated margarines and oils, Sunola oil supplements }\end{array}$ \\
\hline C & No HDM reduction - standard advice and normal washing routines \\
\hline D & $\begin{array}{l}\text { Active dietary intervention - canola margarines and oils, tuna oil supplements } \\
\text { HDM reduction -standard advice, allergen-impermeable covers, acaricide wash } \\
\text { Active dietary intervention - canola margarines and oils, tuna oil supplements }\end{array}$ \\
\hline
\end{tabular}


wheeze in the last 12 months and either parental reporting of diagnosed asthma at age 18 months or 3 or 5 years, or a $>12 \%$ increase in $\mathrm{FEV}_{1}$ after bronchodilator at age 5 .

At age 5, despite effective reduction in HDM allergen levels, there was no difference in asthma between the two groups and no difference in clinical or lung function outcome [26]. At age 8, there was a suggestion that HDM avoidance in atopic individuals did result in a $10.6 \%$ absolute risk reduction in the development of asthma [27],

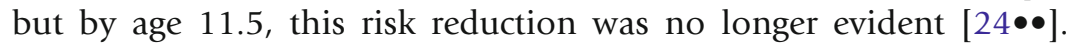
Further analysis of the data seems to suggest that those who went on to develop asthma had mixed food and inhalant sensitisations rather than single-sensitisation profiles [28].

NAC Manchester asthma and allergy study (NACMAAS)

This was a randomised controlled trial recruiting high-risk infants (both parents atopic, mother sensitised to an indoor allergen) living in homes without pets $[29,30]$. In parallel, a low-risk cohort with no pets was followed prospectively [29]. The high-risk participants were randomised to stringent environmental control (allergen-impermeable covers for the mother's and child's beds, weekly hot washing of bed linen, a highfiltration vacuum cleaner for carpets, and hard flooring in the child's bedroom).

Children were assessed at 12 months and 3 years by questionnaires and physical examination [29]. Lung function testing was performed at 3 years [30]. At 12 months, children in the active arm of the study were less likely to have severe wheeze. Lung function was significantly better in the active group at age 3. HDM allergen levels were significantly reduced in the active group, yet interestingly, sensitisation rates in the active group were higher $(p=0.04)$ [30].

The relationship between asthma and atopy was assessed at 11 years in low-risk children who had not undergone active environmental manipulation. Children with early sensitisation to multiple allergens, including mites, pollens, and animal dander, were found to be more likely to have asthma at age 11 than those who remained non-atopic. Lung function parameters were also lower, with more hyperresponsiveness airways in the early-sensitisation group [31•].

Prevention and incidence of asthma and mite allergy (PIAMA) study

PIAMA is a prospective birth cohort study undertaken in the Netherlands between 1996 and 1997 [32] that involved a randomised controlled trial of house dust mite allergen avoidance as well as a

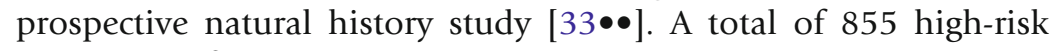
children (defined as those born to allergic mothers) were recruited to the intervention study and randomised to receive mite-impermeable covers and mattresses for the parents'/child's bed or placebo. Questionnaires were completed by parents during pregnancy, at 3 months, and then annually from 1 to 8 years of age [34•]. Parents and children were asked to complete questionnaires at 11 and 14 years,

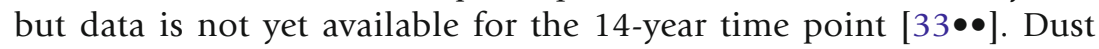
samples, blood samples, and pulmonary function tests (PFTs) were performed at 3 months and $1,4,8$, and 12 years of age. Approximately 400 high-risk children and 2,500 low-risk children were recruited to the natural history group. All high-risk children 
were followed up as described above, along with a random sample of the low-risk children.

Early intervention with mite-impermeable mattress covers was not found to be associated with reduction in mite allergen exposure [34•]. There appeared to be a temporary decrease in asthma symptoms up to the age of 2 years, but by the age of 8 years, there was no difference between the groups. The relative risk (RR) of asthma in the last 12 months was 0.87 (95\% CI; 0.6-1.28), and the RR of bronchial hyperresponsiveness was 1.07 (95\% CI; 0.86-1.33) [34•]. The intervention had no effect on hay fever, eczema, or allergic sensitisation.

\section{Other studies}

The Prevention of Asthma in Susceptible Children (PREVASC), the Canadian Childhood Asthma Primary Prevention Study (CCAPPS), and the Study on the Prevention of Allergy in Children in Europe (SPACE) all looked at primary prevention of asthma by allergen avoidance in infants. No benefits were found in any of these studies, which are summarised in Table 3.

Early non-randomised studies of HDM allergen avoidance in patients with established asthma have shown that moving patients to high altitudes improved their asthma symptoms [18, 35].

A recent prospective observational cohort study recruited patients with severe refractory asthma. Patients were assessed via asthma questionnaire, spirometry, fractional exhaled nitric oxide tests, a 6-minute walking test, and specific IgEs to common aeroallergens at baseline and after 12 weeks at altitude. Of the total 137 patients, 68 were sensitised to HDM, 92 were sensitised to at least one common aeroallergen, and 45 had no sensitisations [36••]. Both HDM-sensitised and non-sensitised patients experienced a significant improvement in their asthma quality-of-life questionnaires at the end of 12 weeks. They also had an improved $\mathrm{FEV}_{1}$ and 6-minute walking distance and a reduction in oral corticosteroid use. Only sensitised individuals were found to have a significant drop in exhaled nitric oxide, although there was not a significant difference between the two groups. Total IgE to HDM also dropped in both groups, but was only significantly reduced in the sensitised group [36••]. High-altitude treatment may be effective in both atopic and non-atopic asthma, suggesting that altitude may have beneficial effects that are not due to allergen avoidance [36••].

A randomised controlled trial on the effect of allergen avoidance on asthma control in primary care was completed in 2010 [37]. The control group consisted of assessment of asthma symptoms, inhaler-technique medication usage, and the provision of self-management action plans. The intervention group had the usual review, but also received an allergy assessment consisting of completion of a structured allergen inventory and asthma trigger inventory, as well as SPTs to common aeroallergens and individual advice about allergen avoidance. 107 patients were randomised to each group. Although there appeared to be an improvement in lung function measured by $\mathrm{FEV}_{1}$ in the intervention group compared to the control group, there was no difference in the perceived symptoms. Furthermore, the intervention group used more medication, suggesting that even targeted allergen avoidance may not have the impact required for adequate asthma management. 
Table 3. A table to summarise other important studies investigating allergen avoidance in infancy

\begin{tabular}{|c|c|c|c|}
\hline & CCAPPS & PREVASC & SPACE \\
\hline Country & Canada & Netherlands & Europe \\
\hline $\begin{array}{l}\text { Study } \\
\text { population }\end{array}$ & High-risk & High-risk & High-risk \\
\hline Design & $\begin{array}{l}\text { Prospective randomised } \\
\text { controlled trial to determine } \\
\text { the effectiveness of a } \\
\text { multifaceted intervention } \\
\text { programme in the primary } \\
\text { prevention of asthma in } \\
\text { high-risk infants in two } \\
\text { Canadian centres }[39,51]\end{array}$ & $\begin{array}{l}\text { A multi-faceted intervention } \\
\text { study to reduce } \\
\text { environmental exposure to } \\
\text { inhalant and food allergens } \\
\text { and cigarette smoke in } \\
\text { genetically susceptible } \\
\text { children [52] }\end{array}$ & $\begin{array}{l}\text { A prospective randomised } \\
\text { controlled trial of } \\
\text { multifaceted design }[53,54] \text {. }\end{array}$ \\
\hline Intervention & $\begin{array}{l}\text { Allergen-impermeable covers } \\
\text { Weekly bed sheet laundering } \\
\text { Acaricide washes } \\
\text { Removal of pets } \\
\text { Smoking cessation advice } \\
\text { Breastfeeding encouraged for } \\
\text { entire first year } \\
\text { Delay introduction of solids until } \\
6 \text { months Cow's milk, peanuts, } \\
\text { and seafood discouraged in } \\
\text { infancy } \\
\text { Avoid day care until after the } \\
\text { first year }\end{array}$ & $\begin{array}{l}\text { Pets to be kept outside } \\
\text { Allergen-impermeable covers } \\
\text { Exclusive breastfeeding to } 6 \\
\text { months } \\
\text { Smoking cessation advice } \\
\text { Avoid solid food and cow's milk } \\
\text { until } 6 \text { months }\end{array}$ & $\begin{array}{l}\text { Exclusive breastfeeding for as } \\
\text { long as possible } \\
\text { Delay solids until } 6 \text { months } \\
\text { Cow's milk, egg, and fish avoided } \\
\text { until } 12 \text { months } \\
\text { Peanut/tree nut avoided until } 3 \\
\text { years } \\
\text { Allergen-impermeable bed covers } \\
\text { Remove carpet from the infant's } \\
\text { room } \\
\text { Hot-wash soft furnishings weekly } \\
\text { Ventilate infant's room at least } \\
\text { once a day and vacuum weekly } \\
\text { Pets and smoking discouraged }\end{array}$ \\
\hline Numbers & 545 & 476 & 696 \\
\hline $\begin{array}{l}\text { Age last } \\
\text { assessed }\end{array}$ & 7 years & 6 years & 2 years \\
\hline $\begin{array}{l}\text { Clinical } \\
\text { outcome }\end{array}$ & $\begin{array}{l}\text { The proportion of children with } \\
\text { probable asthma (as defined } \\
\text { by wheeze in the last } 12 \\
\text { months plus bronchial hyper- } \\
\text { responsiveness) was lower in } \\
\text { the intervention group when } \\
\text { adjusted values were used } \\
25 \% \text { vs. } 12.9 \%(p=0.002 \text { ) } \\
\text { [39]. } \\
\text { Bronchial hyperresponsiveness } \\
\text { was not statistically different } \\
\text { between the two groups. }\end{array}$ & $\begin{array}{l}\text { No significant influence on the } \\
\text { diagnosis of asthma } \\
\text { diagnosis at the age of } 6 \\
\text { years } \\
\text { There was also no effect on the } \\
\text { lung function tests. }\end{array}$ & $\begin{array}{l}\text { No significant difference } \\
\text { between the two groups in } \\
\text { the diagnosis of asthma/ } \\
\text { wheezy bronchitis ( } 18.1 \% \text { in } \\
\text { the active vs. } 17.8 \% \text { in the } \\
\text { control group) ( } 54) \\
\text { The number of children sensitised } \\
\text { to HDM allergen was lower in the } \\
\text { active group, but this was } \\
\text { probably not significant ( } 1.86 \% \\
\text { vs. } 5 \% \text { ) [54]. }\end{array}$ \\
\hline $\begin{array}{l}\text { Additional } \\
\text { information }\end{array}$ & $\begin{array}{l}\text { More of the intervention group } \\
\text { had been to hospital } \\
\text { emergency departments with } \\
\text { wheeze in the preceding } 12 \\
\text { months. } \\
\text { The level of house dust mite } \\
\text { allergen found in the homes of } \\
\text { each group was significantly } \\
\text { different; however, there was no } \\
\text { significant difference in the SPTs } \\
\text { between the two groups. }\end{array}$ & $\begin{array}{l}\text { HDM exposure is low in the } \\
\text { Netherlands, making } \\
\text { improvements difficult. } \\
\text { The number of weeks children } \\
\text { were breastfed didn't } \\
\text { significantly differ between the } \\
\text { groups. }\end{array}$ & $\begin{array}{l}\text { It was postulated that HDM- } \\
\text { induced asthma usually } \\
\text { presents later in childhood, } \\
\text { and an effect may be seen at } \\
\text { a later date. However, a } \\
\text { follow-up was published at } \\
24 \text { months that did not show } \\
\text { any evidence of an } \\
\text { improvement in symptomatic } \\
\text { allergy [55], and no further } \\
\text { follow-up studies have been } \\
\text { published. }\end{array}$ \\
\hline
\end{tabular}


A common assumption in the field of medicine is that factors associated with a disease are causal. Although there is good evidence that atopy is associated with asthma, the evidence for cause and effect is less convincing. In developed countries, up to $40 \%$ of children and young adults are atopic, yet only around one-third of these individuals develop asthma [38]. Additionally, in the above-described multifaceted intervention studies, differences reported in the development of asthma saw no associated reduction in allergic sensitisation [20•, 39]. Indeed, the PIAMA natural history study found no association between allergic sen-

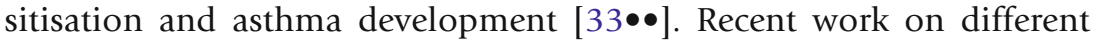
asthma phenotypes also suggests that allergens are not the only drivers of airway inflammation. The 2000 Copenhagen Prospective Study on Asthma in Childhood (COPSAC) found that episodes of wheezing in high risk-children are associated with both bacterial and viral infections, which may be the inflammatory driver in a subset of cases [40].

All of the multifaceted intervention studies encouraged mothers in the active group to breastfeed. Recent work has shown that breastfeeding improves lung function in children, which may in turn impact on the development of asthma [41]. The PIAMA natural history study has also reported a lower incidence of asthma in infants who were breastfed for

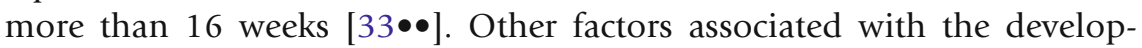
ment of asthma in the PIAMA natural history study include variables not reported in the multifaceted intervention studies, such as:

1. Caesarean section; there was a twofold risk in the development of asthma at age 8 (an effect that was particularly marked if parents were allergic).

2. Being overweight at 6-7 years of age was a risk factor for having both asthma and bronchial hyperresponsiveness at age 8 .

3. Children of mothers who were overweight during pregnancy were more at risk of being asthmatic at age 8, irrespective of the child's BMI.

4. Early day care attendance was associated with increases in airway symptoms up to the age of 4 years, followed by fewer symptoms between ages 4 and 8 years.

5. Air pollution was associated with asthma development at age 8 .

In the studies where allergen avoidance was limited to HDM reduction, there was no difference in the diagnosis of asthma. Indeed, the value of HDM avoidance in asthma has been called into question with the publication of the most recent high-altitude study, conducted in the Alps, that showed benefit even in non-atopic individuals. These benefits may be attributable to lower levels of environmental pollution found in a high-altitude environment, as well as decreased viscosity of air and lower oxygen pressure [36••]. Other possible benefits of this treatment include reduced psychological stress due to the home

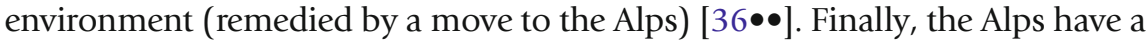
high level of UV light exposure, which is known to increase vitamin D synthesis. The fact that vitamin $\mathrm{D}$ has been implicated as an asthma modulator may play a role in the improvements noted in this study [42]. While observational studies have seemed to indicate that higher vitamin D levels protect against asthma, ongoing clinical trials may help determine whether this really does have an effect [43].

More recently, it has been postulated that Th17 cells may play a role in the development of asthma. Th17 cells are a subgroup of CD4 cells 
that produce a family of IL-17 cytokines. IL-17 controls bronchial hyperresponsiveness and airway remodelling, and high IL-17 levels are often associated with severe asthma [44]. Interestingly, elevated levels of IL-17 also correlate with increased neutrophilic inflammation in asthma [45]. IL-17A has induced steroid insensitivity in bronchial epithelial cells in mouse models [46]. Exactly why this happens and whether allergen sensitisation is involved is not clear, but it could explain the differences in certain asthma phenotypes.

Recent work has suggested that a defective respiratory epithelium may facilitate the passage of allergens into the airway tissue, triggering allergen sensitisation and asthma in susceptible patients [38]. However, another group found that aeroallergen sensitisation preceded virus-induced wheezing, which led them to conclude that preventing sensitisation may reduce the risk of developing asthma [47]. Although rhinovirus-induced wheezing is an independent risk factor for developing asthma, studies have shown that infants under 1 year of age with rhinovirus-induced wheeze and aeroallergen sensitisation are more than twice as likely to be affected with asthma by the age of 6 years [48]. The CCAPPS group analysed exposure to common childhood viruses during the first two years of life, finding that children exposed to respiratory syncytial virus (RSV) and parainfluenza virus (PIV) in the first 12 months were more likely to be diagnosed with new-onset asthma in the second year of life [49]. Indeed, PIV and RSV exposure in the first year of life were independently associated with increased odds of developing asthma, and exposure to PIV was associated with increased risk of persistent asthma. The association between viral exposures and new-onset and persistent asthma was not modified by allergen avoidance [49], and thus the data remain conflicting. The COPSAC 2010 birth cohort may provide additional evidence as to the utility of vitamin D supplementation and the benefits of macrolide antibiotics and administration of influenza vaccine in the development of asthma [50].

In conclusion, there is only limited evidence that primary allergen avoidance is useful in preventing asthma in later years. Further work is needed to determine whether the relationship is causal or casual. The efficacy of allergen avoidance in established asthma was further brought into question by the recent high-altitude data for atopic and non-atopic disease. Viral infections remain the major triggers for exacerbations, but allergens may work synergistically to worsen symptoms. Finally, it is important to remember that asthma is not one disease, and there is no gold-standard definition for diagnosis. Future studies may benefit from better diagnostic criteria and interventions targeted to specific asthma groups in order to better interpret the data that are accumulating.

\section{Compliance with Ethics Guidelines}

\section{Conflict of Interest}

Nicola J. Gray and Anthony J. Frew declare that they have no conflict of interest.

Human and Animal Rights and Informed Consent

This article does not contain any studies with human or animal subjects performed by any of the authors. 
Papers of particular interest, published recently, have been highlighted as:

- Of importance

$\bullet \quad$ Of major importance

1. Vernon MK, Wiklund I, Bell JA, Dale P, Chapman KR. What do we know about asthma triggers? a review of the literature. The Journal of asthma : official journal of the Association for the Care of Asthma. 2012;49(10):991-8. Epub 2013/04/12.

2. Masoli M, Fabian D, Holt S, Beasley R. The global burden of asthma: executive summary of the GINA Dissemination Committee report. Allergy. 2004;59(5):469-78. Epub 2004/04/15.

3. Gupta R, Sheikh A, Strachan DP, Anderson HR. Burden of allergic disease in the UK: secondary analyses of national databases. Clin Exp Allergy. 2004;34(4):520-6. Epub 2004/04/15.

4. Mathur SK. Allergy and asthma in the elderly. Seminars in respiratory and critical care medicine. 2010;31(5):587-95. Epub 2010/10/14.

5. assembly G. Global initiative for asthma management and prevention. http://www.ginasthma.org. 2012.

6. Watson JP, Cowen P, Lewis RA. The relationship between asthma admission rates, routes of admission, and socioeconomic deprivation. The European respiratory journal. 1996;9(10):2087-93. Epub 1996/10/01.

7. Martinez FD, Wright AL, Taussig LM, Holberg CJ, Halonen M, Morgan WJ. Asthma and wheezing in the first six years of life. The Group Health Medical Associates. The New England journal of medicine. 1995;332(3):133-8. Epub 1995/01/19.

8. Dodge R, Martinez FD, Cline MG, Lebowitz MD, Burrows B. Early childhood respiratory symptoms and the subsequent diagnosis of asthma. The Journal of allergy and clinical immunology. 1996;98(1):4854. Epub 1996/07/01.

9. Simpson BM, Custovic A, Simpson A, Hallam CL, Walsh D, Marolia H, et al. NAC Manchester Asthma and Allergy Study (NACMAAS): risk factors for asthma and allergic disorders in adults. Clin Exp Allergy. 2001;31(3):391-9. Epub 2001/03/22.

10. Bacharier LB, Strunk RC, Mauger D, White D, Lemanske Jr RF, Sorkness CA. Classifying asthma severity in children: mismatch between symptoms, medication use, and lung function. American journal of respiratory and critical care medicine. 2004;170(4):426-32. Epub 2004/06/03.

11. BTS. British Guideline on the Management of Asthma. 2008 revised 2012.

12. Martinez FD, Vercelli D. Asthma. Lancet. 2013;382(9901):1360-72. Epub 2013/09/18.

13. Agache I, Akdis C, Jutel M, Virchow JC. Untangling asthma phenotypes and endotypes. Allergy. 2012;67(7):835-46. Epub 2012/05/19.

14. Wenzel S. Severe asthma: from characteristics to phenotypes to endotypes. Clin Exp Allergy. 2012;42(5):650-8. Epub 2012/01/19.
15. Lotvall J, Akdis CA, Bacharier LB, Bjermer L, Casale TB, Custovic A, et al. Asthma endotypes: a new approach to classification of disease entities within the asthma syndrome. The Journal of allergy and clinical immunology. 2011;127(2):35560. Epub 2011/02/02.

16. Rosenstreich DL, Eggleston $P$, Kattan M, Baker D, Slavin RG, Gergen P, et al. The role of cockroach allergy and exposure to cockroach allergen in causing morbidity among inner-city children with asthma. The New England journal of medicine. 1997;336(19):1356-63. Epub 1997/05/08.

17. Simpson A, Tan VY, Winn J, Svensen M, Bishop CM, Heckerman DE, et al. Beyond atopy: multiple patterns of sensitization in relation to asthma in a birth cohort study. American journal of respiratory and critical care medicine. 2010;181(11):1200-6. Epub 2010/02/20.

18. Grootendorst DC, Dahlen SE, Van Den Bos JW, Duiverman EJ, Veselic-Charvat M, Vrijlandt EJ, et al. Benefits of high altitude allergen avoidance in atopic adolescents with moderate to severe asthma, over and above treatment with high dose inhaled steroids. Clin Exp Allergy. 2001;31(3):400-8. Epub 2001/03/22.

19. Custovic A, Simpson A, Chapman MD, Woodcock A. Allergen avoidance in the treatment of asthma and atopic disorders. Thorax. 1998;53(1):63-72. Epub 1998/05/13.

20.• Scott M, Roberts G, Kurukulaaratchy RJ, Matthews S, Nove A, Arshad SH. Multifaceted allergen avoidance during infancy reduces asthma during childhood with the effect persisting until age 18 years. Thorax. 2012;67(12):1046-51. Epub 2012/08/04.

A multifaceted intervention from birth that shows some evidence that allergen avoidance can modify the rates of persistent asthma up to the age of 18 .

21. Arshad SH, Bateman B, Matthews SM. Primary prevention of asthma and atopy during childhood by allergen avoidance in infancy: a randomised controlled study. Thorax. 2003;58(6):489-93. Epub 2003/05/31.

22. Hide DW, Matthews S, Tariq S, Arshad SH. Allergen avoidance in infancy and allergy at 4 years of age. Allergy. 1996;51(2):89-93. Epub 1996/02/01.

23. Arshad SH, Bateman B, Sadeghnejad A, Gant C, Matthews SM. Prevention of allergic disease during childhood by allergen avoidance: the Isle of Wight prevention study. The Journal of allergy and clinical immunology. 2007;119(2):307-13. Epub 2007/02/13.

24.• Toelle BG, Garden FL, Ng KK, Belousova EG, Almqvist C, Cowell CT, et al. Outcomes of the Childhood Asthma Prevention Study at 11.5 years. The Journal of allergy and clinical immunology. 2013. Epub 2013/08/01. 
Despite an effective reduction in house dust mite allergen, rates of asthma were not significantly different between active and placebo groups by the age of 11.5 years, suggesting single allergen avoidance is not sufficient to prevent asthma in high risk children.

25. Mihrshahi S, Peat JK, Webb K, Tovey ER, Marks GB, Mellis CM, et al. The childhood asthma prevention study (CAPS): design and research protocol of a randomized trial for the primary prevention of asthma. Controlled clinical trials. 2001;22(3):33354. Epub 2001/06/01.

26. Marks GB, Mihrshahi S, Kemp AS, Tovey ER, Webb K, Almqvist $\mathrm{C}$, et al. Prevention of asthma during the first 5 years of life: a randomized controlled trial. The Journal of allergy and clinical immunology. 2006;118(1):53-61. Epub 2006/07/04.

27. Toelle BG, Ng KK, Crisafulli D, Belousova EG, Almqvist C, Webb K, et al. Eight-year outcomes of the Childhood Asthma Prevention Study. The Journal of allergy and clinical immunology. 2010;126(2):388-9. 9 e1-3. Epub 2010/07/22.

28. Garden FL, Simpson JM, Marks GB. Atopy phenotypes in the Childhood Asthma Prevention Study (CAPS) cohort and the relationship with allergic disease: clinical mechanisms in allergic disease. Clin Exp Allergy. 2013;43(6):633-41. Epub 2013/05/29.

29. Custovic A, Simpson BM, Simpson A, Kissen P, Woodcock A. Effect of environmental manipulation in pregnancy and early life on respiratory symptoms and atopy during first year of life: a randomised trial. Lancet. 2001;358(9277):188-93. Epub 2001/07/31.

30. Woodcock A, Lowe LA, Murray CS, Simpson BM, Pipis SD, Kissen P, et al. Early life environmental control: effect on symptoms, sensitization, and lung function at age 3 years. American journal of respiratory and critical care medicine. 2004;170(4):433-9. Epub 2004/05/15.

31. Lazic N, Roberts G, Custovic A, Belgrave D, Bishop $\mathrm{CM}$, Winn J, et al. Multiple atopy phenotypes and their associations with asthma: similar findings from two birth cohorts. Allergy. 2013;68(6):764-70. Epub 2013/04/30.

Multiple allergen sensitisations appear to be associated with an increase in the prevalence of asthma at the age of 11 .

32. Brunekreef $B$, Smit J, de Jongste J, Neijens $H$, Gerritsen J, Postma D, et al. The prevention and incidence of asthma and mite allergy (PIAMA) birth cohort study: design and first results. Pediatric allergy and immunology : official publication of the European Society of Pediatric Allergy and Immunology. 2002;13 Suppl 15:55-60. Epub 2003/04/12.

33.• Wijga AH, Kerkhof M, Gehring U, de Jongste JC, Postma DS, Aalberse RC, et al. Cohort profile: The Prevention and Incidence of Asthma and Mite Allergy (PIAMA) birth cohort. International journal of epidemiology. 2013. Epub 2013/01/15. The PIAMA intervention showed no difference between the active and placebo groups at the age of 8 years.

The natural history study showed that a number of other variables including lack of breast feeding and childhood BMI could be implicated in the development of asthma. These variables may not have been taken into account in other intervention studies.
34. Gehring U, de Jongste JC, Kerkhof M, Oldewening M, Postma D, van Strien RT, et al. The 8-year follow-up of the PIAMA intervention study assessing the effect of mite-impermeable mattress covers. Allergy. 2012;67(2):248-56. Epub 2011/10/26.

This study showed that mite allergen avoidance did not modify allergic sensitisations or prevalence of eczema, asthma and hay fever.

35. Peroni DG, Boner AL, Vallone G, Antolini I, Warner JO. Effective allergen avoidance at high altitude reduces allergen-induced bronchial

hyperresponsiveness. American journal of respiratory and critical care medicine. 1994;149(6):1442-6. Epub 1994/06/01.

$36 . \bullet$ Rijssenbeek-Nouwens LH, Fieten KB, Bron AO, Hashimoto S, Bel EH, Weersink EJ. High-altitude treatment in atopic and nonatopic patients with severe asthma. The European respiratory journal. 2012;40(6):1374-80. Epub 2012/03/24.

This paper highlights that high altitude treatment improves both atopic and non atopic asthma, calling into question previous conclusions that the benefits of high altitude treatment are due to allergen reduction.

37. Bobb C, Ritz T, Rowlands G, Griffiths C. Effects of allergen and trigger factor avoidance advice in primary care on asthma control: a randomized-controlled trial. Clin Exp Allergy. 2010;40(1):143-52. Epub 2009/10/02.

38. Holgate ST. Innate and adaptive immune responses in asthma. Nature medicine. 2012;18(5):673-83. Epub 2012/05/09.

39. Chan-Yeung M, Ferguson A, Watson W, DimichWard H, Rousseau R, Lilley M, et al. The Canadian Childhood Asthma Primary Prevention Study: outcomes at 7 years of age. The Journal of allergy and clinical immunology. 2005;116(1):49-55. Epub 2005/07/02.

40. Bisgaard $\mathrm{H}$, Hermansen $\mathrm{MN}$, Bonnelykke $\mathrm{K}$, Stokholm J, Baty F, Skytt NL, et al. Association of bacteria and viruses with wheezy episodes in young children: prospective birth cohort study. BMJ. 2010;341:c4978. Epub 2010/10/06.

41. Dogaru CM, Strippoli MP, Spycher BD, Frey U, Beardsmore CS, Silverman M, et al. Breastfeeding and lung function at school age: does maternal asthma modify the effect? American journal of respiratory and critical care medicine. 2012;185(8):874-80. Epub 2012/02/09.

42. Gupta A, Sjoukes A, Richards D, Banya W, Hawrylowicz C, Bush A, et al. Relationship between serum vitamin $\mathrm{D}$, disease severity, and airway remodeling in children with asthma. American journal of respiratory and critical care medicine. 2011;184(12):1342-9. Epub 2011/09/13.

43. Paul G, Brehm JM, Alcorn JF, Holguin F, Aujla SJ, Celedon JC. Vitamin D and asthma. American journal of respiratory and critical care medicine. 2012;185(2):124-32. Epub 2011/10/22.

44. Wang YH, Voo KS, Liu B, Chen CY, Uygungil B, Spoede $\mathrm{W}$, et al. A novel subset of CD4(+) T(H)2 memory/effector cells that produce inflammatory IL-17 cytokine and promote the exacerbation of chronic allergic asthma. The Journal of experimental medicine. 2010;207(11):2479-91. Epub 2010/10/06. 
45. Alcorn JF, Crowe CR, Kolls JK. TH17 cells in asthma and COPD. Annual review of physiology. 2010;72:495-516. Epub 2010/02/13.

46. Zijlstra GJ, Ten Hacken NH, Hoffmann RF, van Oosterhout AJ, Heijink IH. Interleukin-17A induces glucocorticoid insensitivity in human bronchial epithelial cells. The European respiratory journal. 2012;39(2):439-45. Epub 2011/08/11.

47. Jackson DJ, Evans MD, Gangnon RE, Tisler CJ, Pappas TE, Lee WM, et al. Evidence for a causal relationship between allergic sensitization and rhinovirus wheezing in early life. American journal of respiratory and critical care medicine. 2012;185(3):281-5. Epub 2011/10/01.

48. Jackson DJ, Gangnon RE, Evans MD, Roberg KA Anderson EL, Pappas TE, et al. Wheezing rhinovirus illnesses in early life predict asthma development in high-risk children. American journal of respiratory and critical care medicine. 2008;178(7):667-72. Epub 2008/06/21.

49. Lee KK, Hegele RG, Manfreda J, Wooldrage K, Becker $\mathrm{AB}$, Ferguson AC, et al. Relationship of early childhood viral exposures to respiratory symptoms, onset of possible asthma and atopy in high risk children: the Canadian Asthma Primary Prevention Study. Pediatric pulmonology. 2007;42(3):290-7. Epub 2007/01/25.

50. Bisgaard H, Vissing NH, Carson CG, Bischoff AL, Folsgaard NV, Kreiner-Moller E, et al. Deep phenotyping of the unselected COPSAC2010 birth cohort study. Clin Exp Allergy. 2013;43(12):1384-94. Epub 2013/ $10 / 15$.

51. Chan-Yeung M, Manfreda J, Dimich-Ward H, Ferguson A, Watson W, Becker A. A randomized controlled study on the effectiveness of a multifaceted intervention program in the primary prevention of asthma in high-risk infants. Archives of pediatrics \& adolescent medicine. 2000;154(7):657-63. Epub 2000/07/13.

52. Maas T, Dompeling E, Muris JW, Wesseling G, Knottnerus JA, van Schayck OC. Prevention of asthma in genetically susceptible children: a multifaceted intervention trial focussed on feasibility in general practice. Pediatric allergy and immunology : official publication of the European Society of Pediatric Allergy and Immunology. 2011;22(8):794-802. Epub 2011/07/14.

53. Halmerbauer G, Gartner C, Schier M, Arshad H, Dean T, Koller DY, et al. Study on the prevention of allergy in Children in Europe (SPACE): allergic sensitization in children at 1 year of age in a controlled trial of allergen avoidance from birth. Pediatric allergy and immunology : official publication of the European Society of Pediatric Allergy and Immunology. 2002;13 Suppl 15:47-54. Epub 2003/ $04 / 12$.

54. Halmerbauer G, Gartner C, Schierl M, Arshad H, Dean T, Koller DY, et al. Study on the Prevention of Allergy in Children in Europe (SPACE): allergic sensitization at 1 year of age in a controlled trial of allergen avoidance from birth. Pediatric allergy and immunology : official publication of the European Society of Pediatric Allergy and Immunology. 2003;14(1):10-7. Epub 2003/02/27.

55. Horak Jr F, Matthews S, Ihorst G, Arshad SH, Frischer T, Kuehr J, et al. Effect of mite-impermeable mattress encasings and an educational package on the development of allergies in a multinational randomized, controlled birth-cohort study - 24 months results of the Study of Prevention of $\mathrm{Al}$ lergy in Children in Europe. Clin Exp Allergy. 2004;34(8):1220-5. Epub 2004/08/10. 